\title{
Steps toward an Integrated Approach to Hydrometeorological Forecasting Services*
}

\author{
Susan F. Zevin \\ NOAA, National Weather Service, \\ Eastern Region, Bohemia, New York
}

\section{Abstract}

In the 23years since Hurricane Camille devastated Virginia with 27 inches of rain in 24 hours, a major area targeted for hydrometeorological forecast service improvements has been flood and flash flood forecasting. The first attempts to tackle the problems were event driven. Numerous poststorm analyses led to the definition of meteorological criteria often associated with various types of major flash flood-producing rainfall situations. Individual forecast offices attempted to use these techniques with inconsistent success. Additionally, verification was not carried out on a routine or systematic basis.

In 1979, the National Weather Service (NWS) Eastern Region began to encourage its offices to use precipitation forecasts routinely to anticipate critical flood conditions, rather than awaiting observations of rainfall. However, the implementation of a broadscale programmatic approach to the routine operational use of quantitative precipitation forecasting faced numerous hurdles. Complexities ran the gamut of operational problems; and broadscale efforts to implement the program floundered. At the same time, public and private sector users continued to request more accurate information with better lead time for response. Academic studies showed that in order to gain enough lead time for effective decision making and response, it is essential to incorporate the uncertainty of the precipitation forecast into flood forecast operations.

Within the last five years, the NWS once again introduced the possibility of a disciplined, systematic, scientific application of these ideas in the field of operational forecasting. The NWS modernization has afforded the vehicle to implement these concepts operationally. In parallel, NWS forecasters and university researchers have collaborated on probabilistic approaches to the rainfall forecast problem, integrating theory, method, process, and operations.

Based on 20 years of progressive learning and operational experience, the NWS now has the tools, the understanding, and the scientific and operational capabilities to expand the efforts nationally.

\footnotetext{
*This is a revised version of a speech presented at the National Weather Service's National Heavy Precipitation Workshop, held 1620 November 1993 in Coraopolis, Pennslyvania.

Corresponding author address: Susan F. Zevin, NOAA, National Weather Service, Eastern Region, Bohemia, NY 11716.

In final form 18 April 1994.

(c)1994 American Meteorological Society
}

\section{Introduction}

In the 23 years since Hurricane Camille devastated Virginia with 27 inches of rain in 24 hours, a major area the National Weather Service (NWS) targeted for the hydrometeorological forecast service improvements has been flood and flash flood forecasting. Several occurrences of disastrous flash floods that resulted in major loss of life and extensive property damage demonstrated the need for such improvements. The names are a nightmarish litany in our memoriesCamille, Agnes, Black Hills, Taccoa, Buffalo Gap, Johnstown, Brush Creek, Big Thompson, and Shadyside.

The greater awareness of the operational and theoretical problems of providing flash flood forecast services also helped focus attention on the less spectacular, but equally deadly situations, in which one or two persons are swept away by rapidly formed torrents of water. Statistics consistently have shown that 80-90 percent of the annual flood-related deaths are caused by flash floods. Forty percent of these deaths are related to stream crossing or highway fatalities.

\section{Emergency response}

To respond to the safety needs and damages arising during thunderstorms or heavy downpours, the NWS recognized that local agencies must be able to mobilize public work departments, such as law enforcement and highway maintenance departments. Decisions for the mobilization of personnel and equipment include the following: 1) increasing personnel temporarily by extending shifts, or calling on extra people; 2) locating and positioning equipment and personnel; 3) acquiring additional or special equipment by renting or borrowing from other agencies; 4) determining the type of equipment needed and the 
location and duration of use; and 5) timing of repairs and/or equipment removal.

Decisions for storm responses must be made preceding the occurrence of flash floods or severe storms. For example, at-grade stream crossings must be closed for substantially lower stages than flood. River barges require many hours of lead time in order to relocate to secure moorings prior to the onset of higher river levels. Information from the NWS is needed for the potential of occurrence, areal extent, movement, intensity, and duration of the storms before they occur. This guidance is essential for determining how and when personnel and equipment will be deployed. Knowing that ultimately, the service requirements are defined by the users, we will focus later on an update of progress and requirements for the future.

\section{Magnitude of the problem}

As part of its mission to provide flood warning services, the NWS provides site-specific flood forecasts for 3000 of the approximately 20000 flood-prone communities in the United States. We do a good job of forecasting for these sites. However, floods that form in less than 24 hours and flash floods (i.e., those occurring within 6 hours) continue to challenge forecasters. Much of the difficulty lies in the time it takes to complete the operational forecast procedures, from data collection, to processing, to analysis, to dissemination. Additionally, there are inherent flaws in each of the flood forecast system components (e.g., components of data collection systems may be out for maintenance; there may not be sufficient rainfall data in space and time to forecast accurately the runoff in small basins; and the precipitation forecasts may be inadequate or lacking).

For example, the Shadyside flood in June 1990 resulted from a combination of synoptic-scale and mesoscale features that focused over southeast Ohio to produce a brief period of intense rainfall on saturated ground, causing a devastating flash flood. According to the disaster survey, the small scale of this event and the speed at which it evolved are beyond the detection and warning capability of current NWS field technology and may even approach the limits of improved capabilities expected in the near future.

The service record until now reflects this concern. Verification data from a national sample of flash flood events have shown that $75 \%$ of flash flood warnings are issued with less than 1-h lead time, and more than $50 \%$ are issued when the flood already has been observed.

Lead time for flood watches has averaged approximately 3 hours. But, as we know from Shadyside, the watch often does not evoke the sense of emergency for meaningful response when coverage extends over a wide geographic area. When we can focus on specific basins and vulnerable areas, even the watch becomes a very effective tool for local response-as we have seen recently (August 1992) for the Big Cove (Cherokee Indian Reservation) flash flood in western North Carolina.

\section{Comprehensive methodology}

A comprehensive model of the flood forecast response process envisions a system coupling operational forecasting processes, human response, and economic consequences. When viewed this way, the entire process could be amenable to evaluation of its ex ante economic value; and the performance of alternate system designs could be measured, leading to optimized planning. Scoping further into the components of a systems approach and acknowledging the need for a comprehensive forecasting process, an operational flash flood forecasting system has been conceptualized as having the following major components: a quantitative rainfall observation system; a quantitative rainfall prediction system; a stream-flow forecast component; and linkage to a decision response system.

In addition, the system must be feasible to implement operationally in a number of ways, including routine on-line operation without extensive intervention by forecasters; handling of forecast and observed rainfall data from multiple sources; efficient computations given computer resources; integration with current and planned forecast algorithms and technology; and a probability estimation component in order to incorporate the uncertainties about the observed and forecast data, and to enhance the information provided to decision makers. Implicit in such a framework are the philosophical acceptance by forecasters of their abilities to perform the needed duties, and the availability of the tools required for training and professional development.

Though the systematic portrayal of the forecast response process came more than a decade after Camille, the evolution of warning services intuitively has acknowledged the linkages to users throughout the entire history. NWS approaches to system design necessarily have concentrated on optimizing operational forecasting methods, recursively ingesting new information in a series of improvements. This is offered not as cliche or simplistic articulation of the natural evolution of scientific concepts toward societal improvements, but rather to highlight the sense of community among this small group of dedicated sci- 
entists and engineers, and the dynamic, interactive environment we have created, which has allowed the efficient and expeditious conversion of theory into service.

In a sense, all the studies and work accomplished in the last 20 years have been searches within this framework. The NWS has maintained a vision of an ideal operation for two decades and has made significant strides in several areas. Recently, a comprehensive approach, promulgated by management and accepted by the forecast community, has come into view. Within the last two years, we have been able to clearly demonstrate a comprehensive hydrometeoro-

\section{A comprehensive model of the flood forecast response process envisions a system coupling operational forecasting processes, human response, and eco- nomic consequences.}

logical approach grounded in theory, using analytical solutions, fully applicable and achievable in an operational setting by both hydrologists and meteorologists. Only looking back over these last 20 years of disparate, sometimes halting, variously flawed, and seeming disjoint attempts can one see the wisdom and flow leading to an integrated, systematic, operational, and organizational approach to flash flood forecasting.

\section{Early years}

Earliest proposals for a systematic operational and organizational approach emerged in the wake of disastrous flooding in northern Ohio in July of 1969 , followed by Camille in August. Implemented in 1970 nationwide, the initial approach set criteria for service products based on rainfall intensities and corresponding runoff; a quantitative precipitation forecast; and indications of heavy rainfall based on radar reports. With a requirement for runoff criteria, the first flash flood guidance programs were instituted at the River Forecast Centers (RFCs) by August of 1970. The NWS Southern Region led the way in July with computerized guidance tables. Values were updated by the RFCs on Tuesdays and Fridays. The NWS (then called the Weather Bureau) set up ten Warning Coordination Centers to initiate calls and/or coordinate the program with the National Meteorological Center (NMC). The flash flood guidance was provided to River District Offices, Weather Bureau Forecast Offices, and regional coordination centers to anticipate flood runoff, depending on the best estimate or forecast of rainfall. Information flowed between the meteorological and hydrologic community essentially in one direction (i.e., there was no direct operational contact between the RFCs and other NWS offices prior to or during events).

Even in these early times, the uncertainty of the forecast rainfall and runoff and the impact on decision makers was noted. NMC Newsletter $71-5$ summed up the following difficulties in the operational use of quantitative precipitation forecasts (QPF): only 11 percent correct for 2-inch rainfall; difficulty in QPF forecasting for scattered thunderstorm activity with (isolated) heavy rains; and problems with time distributions of the forecast rainfall. Many forecasters hoped the advent of the NMC Limited-area Fine Mesh (LFM) model would improve the guidance products significantly.

Considerable debate ensued concerning the origination of the precipitation forecast, and who was in the best position and had the best knowledge and information to issue the product to the public. The meteorologist in charge at the Weather Service Forecast Office (WSFO) in Raleigh, North Carolina, wrote the Eastern Region (ER) director in 1971 regarding the pros and cons of which office should issue the alert or watch, the WSFO or the River District Office (now the RFC): "The WSFO, if its program is properly implemented, will have greater knowledge of meteorological events within its area of responsibility than any other Weather Service entity."

Weather Service Operations Manual (WSOM) chapter E-13 (revised 1974) described criteria for issuance of a flash flood alert, watch, or warning in terms of amounts of rainfall required to produce flooding and the amount of rain forecast for the alert period. A watch was defined "if meteorological and antecedent conditions indicate a good probability (greater than 30 percent) that flash floods will develop within a designated area ..." A warning was defined "if flash floodproducing precipitation is reported or its probability (as indicated by radar or other reports) is such that flash flooding is considered imminent (at least 80 percent), or if reliable confirmed reports ... or other causative event make the probability of flash flooding at least 80 percent." There were no databases or verification data to support establishment of these probabilistic criteria. Rather, there was an intuitive sense that, on the average, one of three watches and eight of ten warnings should verify.

However, even with the recognition of the need for both hydrologic and meteorological data, and an interlinking of these in a systematic way, the two 
operational communities pursued solutions on separate organizational and operational tracks-the hydrologists through improvement of RFC guidance products and runoff algorithms (i.e., the runoff component of an integrated system, and technological solutions to the rainfall observing systems); and the meteorologists through quasi-objective identification of potentially heavy rainfall (i.e., the rainfall prediction system). Variously, one would hear throughout the NWS that flash flooding either was a "hydro problem" (if the meteorologists were speaking), or it was a "met problem" (if the hydrologists were speaking)!

Hydrologists took the path leading to development of flash flood alarms, self-help schemes, and automated community flood warning systems, which put the flood identification and response in the hands of the community, basically circumventing the need for systematic NWS involvement in real time. Again, we note the idea of the probability of flash flooding as stated in a November 1971 ER memorandum: “. . . Note under 'REMARKS' any special information you have which may be used to subdivide counties wherein flash flood probabilities vary greatly." This set the stage for NWS scientists to help especially vulnerable communities to be self-sufficient in their flood response plans, and the operational forecasting community could focus on specific locales in the watch/ warning program if potentially heavy rainfall was anticipated.

These community procedures started with local volunteer spotter networks, relying on manual reading of river and raingauges, and telephone reports to local officials. Forecast precipitation was not used, but was implied through use of the watches. This also led to the search for technology solutions-starting with flash flood alarms.

Developed initially in the early 1970s, the alarms were expensive, experimental systems. These systems by passed the need for precipitation data and forecasts; and with the alarm sounding in a local Emergency Operations Center (EOC), decision making and response were entirely in the hands of the local community. There was no direct feedback in real time to the NWS; the alarm provided warning basically for one point (or reach) along the affected stream, giving lead time to the community equal to the travel time of the flood wave. Other communities in the basin remained vulnerable. The alarms were deemed excellent for the single warning purpose, too expensive for the NWS to invest in, and not profitable for industry to produce. By 1973, the project was abandoned as not being operationally feasible on a large scale. However, the concept of this type of alarm remained as one of the best solutions for specific flash flood-prone basins.

\section{Deterministic methodologies}

In 1978, a National Flash Flood Program Development Plan signaled the first NOAA-wide recognition of the need for a coordinated nationwide program with specific goals and objectives, and appropriated funds. The plan recognized the progress made in a number of areas, including the burgeoning use of self-help schemes, the expansion of NOAA weather radio, the implementation of the NWS Automation of Field Operations and Services (AFOS) System, and improvements in hydrologic modeling. A 5-yr schedule of activities was built on a modular concept-implementing regionalized programs in high-risk areas supported by centralized facilities for forecasting heavy precipitation, mesoscale analysis and monitoring of weather as it develops, and alerting field offices to the potential of flash floods. The plan relied heavily on developing a prototype automated flood warning module to cover the highest risk area-a 12-county nucleus at the intersection of Kentucky, West Virginia, and Virginia. In the plan, emphasis shifted from the more expensive river stage alarm to the less expensive, but spatially more comprehensive, network of raingauges. Over the years, these networks, linked with automated data collection software in various combinations, resulted in a spectrum of automated flash flood warning systems.

For example, directly born from the national program prototype, the Integrated Flood Observing and Warning System (IFLOWS) solved the flood problem with raingauge networks linked to county and state emergency communications systems rather than as basin-specific systems. With two-way voice and data communications systems and interlinked computers, the system was designed so that NWS and state/local officials could exchange information in real time. In addition, a site-specific flash flood hydrologic forecast model was developed that makes use of observed rainfall data from IFLOWS, along with RFC-produced flash flood guidance, to generate flash flood forecasts at flood-prone locations.

Automated Local Evaluation in Real-time (ALERT) systems were a breakthrough in service provision primarily in the NWS Western Region. Relying on point rainfall from basin-specific networks of automatic reporting gauges, ALERT systems are located in, and used directly by, communities to minimize time between detection and warning. In an effort to extend the lead time for response, some of the automatic algorithms project rainfall 15 minutes into the future by using persistence based on observed data.

The concept of an automated flood warning system is deceptively simple. However, the extreme difficulty of designing and implementing the communications 
and raingauge networks can take years. The intensive resources needed to maintain the systems are major drawbacks to more comprehensive national coverage. These challenges effectively have stunted the spread of the systems to more than the most obviously vulnerable communities. Hence, the dream of the national program development plan never was consummated.

Thousands of flood-prone communities continued to be served during the ensuing years through the watch/warning program. Efforts in the meteorological community from the early 1970 s continued to be focused on improvements to the watch/warning program and the identification of potential flash flood-
MDR was that it directly related rainfall to flash flooding, thus accounting for all the uncertainty in models, measurements, parameters, and initial conditions in one variable. In addition, this approach was simple, efficient, and computationally pleasing. However, lumping all of the uncertainties also took away the flexibility for linking the program with other observation and input systems. In addition, the sample of flash floods on which the probabilities were based had biases with respect to location within a particular administrative region. Therefore, the technique could not account for local variations, which contribute to flash flooding.

Concentrating specifically on the longer-term prediction problem, the Heavy Precipitation Branch (HPB) of the NMC was created in 1977 specifically to focus on the potential for severe floods and flash floods. With only four people for partial 24-h coverage, HPB began its mission with 24-h hand- producing rainfall. Keying on the link between the rainfall observation component and the runoff component of the comprehensive system, the Manually Digitized Radar (MDR) efforts related the occurrence of flash floods in the southern NWS administrative area to the radar reflectivity values from which estimates of rainfall rates (intensities) were taken. This system was manual. Each MDR table indicated the probability relationships between the heavy rain estimates and the potential for flash flooding.

The Tulsa RFC developed a computer program relating accumulated rainfall to the flash flood runoff criteria issued by NWS RFCs. This was the first link between a rainfall observation and the runoff prediction system for evaluation of flash flood potential. The MDR approach to assessing flash flood potential gained acceptance by forecasters for its simple application. These forecasters would, otherwise, have no objective criteria on which to base their watches or warnings. The MDR program and its subsequent relation to flash flood rainfall criteria was a major first step toward incorporating objectivity into flash flood forecasting.

MDR and its enhancements, however, lacked several important elements that characterize a comprehensive system. First, the system did not allow for the incorporation of forecast rainfall. Although MDR accounted for errors in the rainfall observations, the approach did not provide for integration of data from other systems. Also, both a plus and a minus for the drawn products, later adding the 6-h panels. By making use of the RFC data files on the central computer, HPB retrieved the flash flood guidance amounts for comparison with the national forecast rainfall product. This was the first product that involved the real-time interlinking of the meteorological forecast component with precomputed rainfall criteria.

Efforts by local forecasters also flourished in the 1970 s by targeting the specifics of the forecast area, and by incorporating past experience during flash flood-producing rainfall situations with local physical, geographical, and population characteristics. To cover the more extreme events, forecasters performed poststorm analyses of the meteorological characteristics associated with numerous flash flood-producing rainfalls. Southern Region forecasters worked on a view of the limited area QPF, which grew from the Palo Duro Canyon floods, the knowledge of which extended throughout the Southern Region into the mid1980s. The knowledge gained from these analyses was used to train meteorologists, and was promulgated as general guidance available to forecast offices. The information was used subjectively and was not linked objectively to other real-time forecast procedures. The studies recognized the regional characteristics of the most lethal types of storms and were the first attempts by forecasters to provide localized QPFs, an important step as local forecasters tried to apply their skills to such special forecasts. Nonetheless, the operational implementation of these techniques eluded 
forecasters-results were inconsistent from storm to storm, there was no technology base by which to ingest the QPF, no programmatic framework or guidelines were available for local forecasters to follow, no formal tracking or verification of results were produced. Still, our hats are off to these pioneers who pointed the way toward an understanding of regional processes and subsynoptic scale signatures.

\section{NWS Eastern Region emphasis}

The Northeast River Forecast Center was the first RFC to ask permission to use QPFs as input to its realtime river forecasting program. The purpose was twofold: to extend the lead time for forecasts of Flood Stage and Crest Stage, and to reduce "stair stepping"- the successive forecasting of higher river stages for a single forecast point during a prolonged flood event-in river forecasts. With the use of QPF in the initial release, the forecaster could reduce the number of revisions required. Seizing on the merits of this latest forecasting methodology, the Eastern Region implemented the program regionwide in 1979.

The program immediately ran into opposition from field personnel. From hydrologists, there were concerns about conversion from point QPFs to mean areal precipitation values and the lack of confidence in rainfall predictions. Meteorologists voiced concerns about staff workload, computer resource limitations, and the general lack of confidence in their abilities to produce such localized and special forecasts from event to event.

The ER program continued the NWS-wide tradition of organizational solutions, again keying on the role of the local forecast office to interact directly with its associated River Forecast Center. A national program of Critical Flood Support Offices (CFSOs) was mandated. The role of the CSFO was to tailor the NMC QPF and temperature products for RFC operational use during designated critical flood periods. In tailoring the QPF products for the RFC, the CSFO began with the NMC manual and model output as guidance, then modified the amounts subjectively to obtain basin averages. The latter characteristic of the QPF, that of average basin QPF, was a significant departure from previous definitions and uses of QPF, and forced yet another key real-time operational linkage between RFCs and WSFOs. In addition, this average basin QPF could be verified against a volumetric value based on observed rainfall as determined by the RFC.

Amid growing recognition of the potential improvements to service programs, especially in the wake of disastrous floods in the Appalachian Region in November 1985, the program reached a further mile- stone in 1987 when the Charleston, West Virginia, WSFO began a program to provide daily QPF to the Ohio RFC. QPFs were issued early in the morning and updated in the evening, allowing enough lead time for input to the operational river forecasting models. This enhanced the experience of the WSFO forecasters to view their areas of responsibility in terms of basin response for every precipitation event. Other ER offices soon followed suit. Following the Charleston example, daily QPF support to the Ohio RFC was begun by the WSFO Pittsburgh forecasters in 1988, giving estimates of the areal average precipitation amounts for eight individual basins over a 24-h forecast period. The Ohio RFC was involved from the start of the program, helping to define the basins according to input requirements of the river forecast models, and by explaining the need for and operational significance of basin-tailored QPFs to the users. The Boston WSFO contributed a program that transformed handdrawn isohyetal analyses to basin average precipitation suitable for input to the Northeast RFC forecast system. Building on that program, WSFO Cleveland automated the hand-drawn portion of the program, and converted the output areal precipitation to a format suitable for transmission to the RFC.

This cascade of operational applications from one office to another signified a growing grass roots recognition of the need for and capability of field forecasters to produce QPFs. The Ohio RFC continued its training and indoctrination workshops with each WSFO in the Ohio Basin. With nudging from station managers and the Southern and Central Regional Directors, and sometimes grudging acceptance by WSFO staffs, by 1991 all eight WSFOs in the Ohio RFC area of responsibility were contributing daily QPFs to that forecast center's operations. The system has evolved into a gridded format for general operational use, as well as for input to the new interactive computer programs being used to demonstrate NWS modernization concepts.

\section{Probabilistic methodology}

We note that the initial operational developments were focused primarily on single basin average QPFs and associated runoff values. These efforts were trying to gain the same accuracy in the rainfall forecasts as were inherent in rainfall observations. However, it was obvious to others that this was a naive goal on our part. Both the academic community and NWS program interests began to view forecasting problems from more comprehensive perspectives of the users.

In 1965, the first national public releases were made for probability of precipitation occurrence. The 
advent of high speed digital computers, an extensive data archival system, and advances in numerical weather prediction models allowed the NWS to develop automated procedures to produce forecasts of numerous meteorological variables-the model output statistics (MOS). It was the development and implementation of MOS in the mid-1960s that led to the routine use of probability forecasts by the Weather Bureau in its public forecasts.

Significant contributions based on MOS techniques made use of archived manually digitized radar data and precipitation output from the LFM. Two objective forecasts of heavy precipitation, one for the zero to 6$\mathrm{h}$ and one for the 3- to 9-h time periods, were produced on an operational basis in the late 1980s. Data were stratified by regions of the country for spring, summer, and fall seasons. These MOS products were, in a sense, updating schemes, making heavy use of hourly surface and manually digitized information combined with climatic frequencies of precipitation amounts. Verification and comparison with other nationally produced QPFs showed that the MOS product scored well for the 0-6-h time frame and during the evening hours.

Thus, the first 15 years after Camille saw numerous efforts in three of the primary components of the forecasting process: the rainfall observation systems; the rainfall prediction systems; and the runoff algorithms. All activities were pointing to some future realtime integration of the components. However, development of the linkage to a human response system and a model for economic evaluations remained.

\section{Value of probabilistic forecasts}

The mid-1980s saw a significant change in viewing the value of probabilistic forecasts. Most economic evaluations were usually performed based on an ex post approach in which the value of the forecast is measured after the forecasts and events have occurred. In contrast, for an ex ante approach to the value of probability forecasts, the expected value of the forecast is measured before the preparation of the forecast and the observation of weather events. The economic evaluation makes use of a model to minimize expected expenses associated with a response that depends on a weather forecast. The lowest expected expenses are achieved by minimizing the expected sum of costs for the response, and the losses associated with the occurrence of adverse weather events. The analysis is carried through successive stages of decision making by the forecast user as new forecasts are received.

For example, one decision model used Bayesian decision theory in the use of categorical and probabilistic forecasts in short-term scheduling of power generation based on a single period power load forecast transformed from a temperature forecast. This was the first study to apply decision models to be used for the evaluation of continuous variables; in this case, 12-24-h categorical and probabilistic forecasts of temperatures.

Researchers at The University of Arizona also completed several projects beginning in the early 1980s to determine the efficiencies and benefits of flood forecast systems. They determined the value of categorical flood forecasts by calculating the expected annual reduction of losses by modeling the total forecast, dissemination, decision, and response process. They tested the effect of various response strategies and potential improvements on the worth of the systems.

Further development of a total forecast system methodology came in the early 1990 s from the University of Virginia with a computerized meteorological forecasting aid providing a framework for the judgmental process. This approach included the use of local climatological guidance, the integration of information from numerical and statistical guidance products, and forecaster input to a hydrologic (river stage) forecast system. Out of this work has come methodologies for comparison of alternate forecast systems, and evaluation of the reliability of warning systems.

\section{Decision methodologies}

The forecaster's intuitive aggregation, assimilation, and use of information as a subjective forecasting process in the Bayesian framework was first described in 1971. Following on this, NWS and The University of Arizona researchers investigated the application of Bayesian decision theory to the flood and flash flood forecasting problem. With advances in technology, especially with respect to data collection and analysis of mesoscale weather features, and considering the high costs (time and personnel) for repair of damages versus those associated with preparation for response, it was recognized that the NWS could serve sophisticated users better through the provision of probabilistic forecasts of flash floods.

The probability of flash flooding for a specific forecast period could form the basis for public issuance of flash flood watches or warnings, depending on preset criteria for the local forecast area. Or, where more sophisticated users were involved, the output could be used for mobilizing resources, staff, and equipment. The ability of local agencies to prepare for flooding, based on a probability forecast, would be more cost 
effective than awaiting issuance of a flash flood watch or warning under current forecast operations. Hence, a Bayesian framework was developed that explicitly updated the probabilities. The probability of a flash flood is the probability that potential areal rainfall over the forecast period, conditioned on the forecast information, exceeds the resultant rainfall-generated runoff (when aggregated within the stream), and overtops the stream banks to produce flooding.

In a follow-up study it was shown that certain NWS operational parameters, that is: objective precipitation forecasts, were feasible surrogates for likelihoods in a Bayesian methodology. Other methods were proposed which used subjective forecasts to formulate conditional probabilistic QPFs based on conditional probability of occurrence and amounts of precipitation. The studies pointed out that skill in the subjective forecasts could be improved with the use of climatology. Some of the methodologies used point probabilities, others assumed the use of areal probabilities.

Other theoretical and academic studies addressed the individual components of a flood forecasting system, either rainfall runoff models or improved measurement systems or forecast rainfall models. Several researchers made extensive use of the concept of state space modeling. In these methods, analytical solutions usually were not available, and the form of equations was not computationally efficient. Numerical solutions required an approximation of distributions through a finite set of parameters. Often the formulation was valid and applicable, but not implemented in real-time operations because of an inability to derive the requisite probability distributions, and due to the lack of computational power for calibration and real-time solution.

\section{Practical applications}

Building on new insights into the economic value of forecast systems and theoretical insights into probabilistic approaches, 20 years of operations, applications, and theoretical development converged at WSFO Pittsburgh in May of 1990. As noted previously, the forecasters had been preparing area QPFs since June 1988 for eight basins of the upper Ohio River. Verification scores indicated positive skill in both 24-h and 6-h amounts, with an obvious bias toward overforecasting.

Again, highlighting a key linkage between operational hydrology and meteorology, it was shown clearly that, in order to be of use in river forecasting, the areal QPF must reflect the basin weighted average of precipitation, similar to the weighted averaging (such as Theissen polygons) used by hydrologists to determine observed basin precipitation. A second major aspect was highlighted by the WSFO Pittsburgh forecasters. They indicated that, although they found national guidance (model and MOS) helpful, it was not directly applicable for their use in converting to areal average QPF.

It was further proposed that probabilistic QPF could be specified by three exceedance fractiles describing uncertainty in a forecast of the areal average precipitation amount expected during 24 hours from the forecast time. In addition, the 24-h amount could be disaggregated into 6 -h amounts describing the timing of the rainfall over the forecast period.

Mirroring these innovative thoughts, training workshops were held at WSFO Pittsburgh with follow-up interactive sessions-methodology was tested, then modified according to forecaster input. Training included interpretation of verification results, understanding the thought processes to identify biases in the forecasts, and probabilistic reasoning to enhance judgmental skills. Additionally, the verification scores were shared regularly with the forecasters, with immediate feedback on the forecaster's next shift, and a more thorough review of individual results at the end of each month. Each forecaster also was made aware (confidentially) of his/her individual verification scores. This collaborative effort between WSFO Pittsburgh and the University of Virginia, funded under the Cooperative Program for Operational Meteorology, Educational, and Training (COMET) auspices, has been a model partnership of forecasters and academics, theory and operations.

This novel forecast methodology consists of a computerized forecasting aid, provides a framework for the judgmental process, displays local climatological guidance, facilitates the integration of information from dynamical and statistical guidance products, and takes the forecaster's input and prepares the final product for transmission to the Ohio RFC.

Results of this experiment over time have shown that forecasters can produce probabilistic QPFs, which can be input directly into hydrologic forecast models, and, therefore, are potentially valuable for flood forecasting; and that such forecasts can be formulated within the normal duties and responsibilities of the forecast shift. The forecasters, initially reluctant to take on the project, now consider these forecasts a matter of routine, and their skill is regarded with considerable pride. The original 1971 memo from the meteorologist in charge of WSFO Raleigh was prophetic. The forecasters at Pittsburgh discovered that they possessed the most complete knowledge of hydrometeorological events within their area of responsibility. 


\section{Summary}

The last 20 years have seen a steady march by operational forecasters and theoreticians toward a comprehensive procedure for forecasting flash floods. From the earliest plans, there have been consistent appeals for operationally feasible systems, which would integrate meteorological variables with hydrologic criteria. The notion of probabilistic forecasts of rainfall and flooding have been a part of the envisioned solution every step of the way. Successes were borne from operational efficiency and organizational necessity, and supported by interested and challenged scientists and engineers convinced of the promise of service to the public.

Today, we are at a watershed in our pursuit of those original goals of a nationwide flash flood forecast program. All of the work up until now has been developmental, through incremental grass roots field efforts and through successive jumps in the application of statistical and decision theories. Now, looking back to those first steps, it seems we have known all along where we needed to be going. Through many previous studies and experimentation in an operational environment, we have identified the components, their theoretical constructs, analytical solutions, and operational procedures. These efforts are no less than world class-with breakthroughs in the real-time application of Bayesian methodology and decision theory on spatial and temporal scales. They come at the prescient moment in National Weather Service history, when we are implementing the technologies, such as the new Doppler Radar Network and the Advanced Weather Information Processing System, that finally can support the efficient computation and ingest of the requisite data. Unlike other NWS activities that are tests of the ingest of data and the use of technologies in an operational framework (and I do not minimize the significance of these), these QPF activities are bold operational manifestations of scientific theory fully integrated into the forecast process on a day-by-day basis.

Now, we enter an era of implementation. We have developed the experience and the tools needed to take us into the next phase of forecast methodology. We must continue our work toward a better understanding of the physical meteorological processes while exploring with our fabulous new detection equipment. Though the developmental work is far from complete, we must not wait longer to convince ourselves that, in the words of that 1971 memorandum: "The WSFO, when its program is properly implemented, does have greater knowledge of meteorological events within its area of responsibility than any other weather service entity."
Acknowledgments. During the past 20 years, many dedicated pioneers contributed to the dramatic progress outlined by this presentation. The accomplishments of most of these individuals is described within the documents that comprise the attached list of related references.

\section{Appendix}

Significant references contributing to the progress of hydrometeorological forecasting.

Alexandridis, M. G., and R. Krzysztofowicz, 1981: Value of categorical and probabilistic temperatures forecasts for scheduling of power generation. Report Number 282, Ralph M. Parsons Laboratory, Hydrology and Water Resource Systems, MIT, Cambridge, MA.

Arkell, R. E., and R. E. LaPlante, 1991: Verification of river stage quantitative precipitation forecasts. Eastern Region Technical Attachment, No. 91-5A, National Weather Service, NOAA, U.S. Department of Commerce, 7 pp. [Available from NWS Eastern Region Headquarters, Scientific Services Division, 630 Johnson Ave., Bohemia, New York, 11716.]

Belville, J., and N. O. Stewart, 1984: Extreme rainfall events in Louisiana, the New Orleans type. Preprints, Fifth Conf. on $\mathrm{Hy}$ drometeorology, Tulsa, Amer. Meteor. Soc., 284-290.

—, G. A. Johnson, and J. D. Ward, 1978: A flash flood aid-the limited area QPF. Preprints, Conf. on Flash Floods: Hydrometeorological Aspects and Human Aspects, Los Angeles, Amer. Meteor. Soc., 21-28.

Bras, R. L., 1976: Short-term forecasting of rainfall and runoff. ASA Workshop on Recent Developments in Real-time Forecasting of Water Resource Systems, Luxemburg, Austria, 125-137.

Charba, J. P., 1987: Features of an operational objective 0-6 and 3$9 \mathrm{H}$ system for forecasting heavy precipitation amounts. Preprints, Seventh Conf. on Hydrometeorology, Edmonton, Amer. Meteor. Soc., 137-142.

- J. T. Moeller, and P. D. Yamamoto, 1988: Performance of operational objective $0-6 \mathrm{H}$ quantitative precipitation forecasts relative to manual and model generated forecasts: A preliminary assessment. NOAA Tech. Memo., NWS TDL 79, National Oceanic and Atmospheric Administration, U.S. Department of Commerce, $31 \mathrm{pp}$.

Davis, D. R., and T. O. Keefer, 1989: Likelihoods for probabilistic flash forecasting. National Weather Service Cooperative Agreement NA 87AA-H-HY127, Department of Hydrology and Weather Resources, $98 \mathrm{pp}$.

Davis, R. S., and W. J. Drzal, 1991: The potential use of WSR-88D digital rainfall data for flash flood applications on small streams. Natl. Wea. Dig., 16 (2), 2-18.

Environmental Science Services Administration, 1969: The Virginia Floods, August 19-22, 1969: Report to the Administrator. U.S. Department of Commerce, $25 \mathrm{pp}$.

Faivre, B., N. Merrill, B. Shaw, T. Synderman, and E. Volles, 1992: Design of Human-Computer System for Probabilistic River Stage Forecasts. Department of Systems Engineering, University of Virginia, Charlottesville, VA., 2-7.

Funk, T. W., 1991: Forecasting techniques utilized by the Forecast Branch of the National Meteorological Center during a major convective rainfall event. Wea. Forecasting, 6, 548-564.

Georgakakos, K.P., and R. Bras, 1982: A precipitation model and its use in real-time river forecasting. Report Number 286, Ralph M. Parsons Laboratory, Hydrology and Water Resource Systems, MIT, Cambridge, MA 
Hughes, L. A., 1980: Probability forecasting-Reasons, procedures, problems. NOAA Tech. Memo., NWSFCST24, National Oceanic and Atmospheric Administration, U.S. Department of Commerce, $84 \mathrm{pp}$.

Johnson, E. R., and R. Bras, 1978: Short term rainfall prediction: A non-stationary multivariate stochastic model. Report Number 233, Ralph M. Parsons Laboratory for Water Resources and Hydrodynamics, MIT, Cambridge, MA.

Kachic, A. S., and S. G. Summer, 1990: Use of quantitative forecasts in the Eastern Region hydrology program. Eastern Region Technical Attachment, No. 90-5C. National Weather Service, NOAA, U.S. Department of Commerce, 3 pp. [Available from NWS Eastern Region Headquarters, Scientific Services Division, 630 Johnson Ave., Bohemia, New York, 11716.]

Kitanidis, P. K., and R. Bras, 1978: Real-time forecasting with a conceptual hydrologic model. Part 2: Applications and results. Water Resources Research, 16 (6), 1034-1044.

Krzysztofowicz, R., 1983: Why should a forecaster and a decision maker use Bayes Theorem. Water Resources Research, 19 (2), 327-336.

_ 1985: Choice of action based on the probability of a flash flood Report to Office of Hydrology, National Weather Service, National Oceanic and Atmospheric Administration, U.S. Department of Commerce, School of Engineering and Applied Science, University of Virginia, Charlottesville, VA.

$\ldots$, 1992: Performance tradeoff characteristic of a flood warning system. Water Resources Bulletin, 25 (1), 193 pp.

_ , and D. R. Davis, 1983: A methodology for evaluation of flood forecast-response systems. Part 1: Analysis and concepts. Water Resources Research, 19 (6), 1423-1430.

_- and D. Long, 1991: Forecast sufficiency characteristic: Construction and application. International Journal of Forecasting, 39-45.

_ and T. R. Drake, 1992: Probabilistic quantitative precipitation forecasts for river forecasting. Preprints, Symp. on Weather Forecasting, Atlanta, Amer. Meteor. Soc., 66-71.

_ J. S. DuBois, and D. Long, 1992: Reliability of flood warning systems: Methodology and case studies. Report to Institute for Water Resources, U.S. Army Corps of Engineers, School of Engineering \& Applied Science, Charlottesville, VA., 3 pp.

_ W. W. J. Drzal, T. R. Drake, J. C. Weyman, and L. A. Giordano, 1993: Probabilistic quantitative precipitation forecasts for river basins. Wea. Forecasting, 8, 424-439.

Maddox, R. A., L. R. Hoxit, and F. Canova, 1980: Meteorological characteristics of heavy precipitation and flash flood events over the western United States. NOAA Tech. Memo., ERL APCL-23, National Oceanic and Atmospheric Administration, U.S. Department of Commerce, $87 \mathrm{pp}$.

May, H. T., 1977: A comparison of the frequency distribution of fourhour totals of manually digitized radar data with flooding over a portion of the southeastern United States. NOAA Tech. Memo. NWS SR-90, National Oceanic and Atmospheric Administration, U.S. Department of Commerce, $22 \mathrm{pp}$.

Moore, P. L., and D. L. Smith, 1979: Manually digitized radar data interpretation and application. NOAA Tech. Memo., NWS SR-99, National Oceanic and Atmospheric Administration, U.S. Department of Commerce, $24 \mathrm{pp}$.

Muller, B. M., and R. A. Maddox, 1979: A climatological comparison of heavy precipitation and flash flooding. American Meteorological Society.

Murphy, A. H., 1981: Subjective quantification of uncertainty in weather forecasts in the United States. Meteor. Rundsch. 65, 75-76.
_ 1991: Probabilities, odds, and forecasts of rare events. Wea. Forecasting, 6, 302-307.

- , and Q. Ye, 1990: Comparison of objective and subjective precipitation probability forecasts: The sufficiency relation. Mon. Wea. Rev., 118, 1783-1792.

— W. Wsu, and R. L. Winkler, 1982: Subjective probabilistic quantitive precipitation forecasts. Proc. Ninth Conf. on Weather Forecasting and Analysis, Seattle, Amer. Meteor. Soc., 94-100.

National Oceanic and Atmospheric Administration, 1972: Black Hills Flood of June 7, 1972. Natural Disaster Survey Report 72-1, U.S. Department of Commerce, $20 \mathrm{pp}$.

_ 1977: Kansas City, flash flood of September 12-13, 1977. Natural Disaster Survey Report 77-2, U.S. Department of Commerce, $49 \mathrm{pp}$.

_ 1978: National Flash Flood Program Development Plan, FY 1979-1984, U.S. Dept. of Commerce, 47 pp.

_ 1993 : Surveillance System for Natural Disasters. Natural Disaster Survey Report. American Red Cross Centers for Disease Control Collaborative Project on conditions surrounding morbidity and mortality associated with flood and hurricane disasters, U.S. Department of Commerce, 3-4.

National Weather Service, 1982: Automated local evaluation in real time, A cooperative flood warning system for your community. National Oceanic and Atmospheric Administration, U.S. Department of Commerce.

$\ldots, 1991$ : Shadyside, Ohio flash flood of June 14, 1990. Natural Disaster Survey Report, National Oceanic and Atmospheric Administration, U.S. Department of Commerce, $124 \mathrm{pp}$.

_- 1992: Puerto Rico flash floods of January 5-6, 1992. Natural Disaster Survey Report, National Oceanic and Atmospheric Administration, U.S. Department of Commerce, $86 \mathrm{pp}$.

Newton, M. C., 1984: A plan for the development of an automated flash flood monitoring and alert system. National Oceanic and Atmospheric Administration, U.S. Department of Commerce, National Weather Service, Office of Systems Development, Techniques Development Laboratory.

Olson, D. A., 1984: A discussion of the heavy precipitation branch operation. Preprints, Fifth Conf. on Hydrometeorology, Tulsa, Amer. Meteor. Soc., 247-251.

Scofield, R. A., 1978: Using satellite imagery to detect and estimate rainfall from flash flood producing thunderstorms. Preprints, Conf. on Weather Forecasting and Analysis and Aviation Meteorology, Silver Spring, Amer. Meteor. Soc., 132-141.

Wilks, D. S., 1990: Probabilistic quantitive precipitation forecasts derived from PoPs and conditional precipitation amount climatologies. Mon. Wea. Rev., 118, 874-882.

Winkler, R. L., and A. H. Murphy, 1971: Probability forecasting: The aggregation of information. Proc. Int. Symp. on Probability and Statistics in the Atmospheric Sciences, Amer. Meteor. Soc., 8389 .

- and - 1979: The value of weather forecasts in the cost-loss ratio situation: An ex ante approach. Proc. Sixth Conf. on Probability and Statistics, Amer. Meteor. Soc., 83-89.

Zevin, S. F., 1986: A probabilistic approach to flash flood forecasting, Ph.D. Dissertation, University of Arizona, 16-27.

— , and D. R. Davis, 1985: A probabilistic approach to flash flood forecasting. NOAA Tech. Memo., NWS SR-112, U.S. Department of Commerce, 99-106.

,-- , and S. Shields, 1983: A decision theoretic approach to flash flood forecasting. Tech. Conf. on Mitigation of Natural Hazards Through Real-Time Data Collection Systems and Hydrological Forecasting, Sacramento. 